www.jmscr.igmpublication.org

Index Copernicus Value: 79.54

ISSN (e)-2347-176x ISSN (p) 2455-0450

crossrefDOI: https://dx.doi.org/10.18535/jmscr/v7i3.133

\title{
A Clinical Study to Determine Predictive Factors for Difficult Laparoscopic Cholecystectomy
}

\author{
Authors \\ Dr H.B. Janugade ${ }^{1}$, Dr Parth Yadav ${ }^{2}$ \\ ${ }^{1}$ Professor, Dept of General Surgery \\ ${ }^{2} \mathrm{PG}$ Student
}

\begin{abstract}
Background: Laparoscopic cholecystectomy is one of the most common surgeries performed and has replaced open cholecystectomy. Laparoscopic cholecystectomy is associated with better preservation of immune function and a reduction of the inflammatory response compared with open surgery.

Objective: To evaluate the predictive factors responsible for difficult laparoscopic cholecystectomy.

Material and Methods: The present prospective study was conducted in Department of Surgery from September 2016 to October 2018. A total sample size of 67 patients admitted in the department of various surgical wards in tertiary health center with diagnosis of cholelithiasis/ cholecystitis who were clinically evaluated and confirmed by USG included in the study population. Patients below 18 years of age, with $C B D$ calculus, raised ALP, dilated, CBD, where CBD exploration was needed, obstructive jaundice ant not willing for laparoscopic cholecystectomy were excluded. The study was conducted after taking ethical clearance from the institute and informed consent from the patients. The data was collected and analysis done by SPSS version 22.

Results: The maximum numbers of cases were in the age group of 51-60 years (28.36\%), with female dominance (68.66\%) Chronic recurring pain was the main symptom seen in all 67 patients. The rate of conversion from laproscopic cholecystectomy to open cholecystectomy was $8.96 \%$. BMI, H/O acute cholecystitis, thick wall, impacted stone and Pericholecystic collection showed statistical significant association with pre operative score.

Conclusion: The preoperative scoring is statistically and clinically a good test for predicting the operative outcome in laparoscopic cholecystectomy.

Keywords: Laproscopic cholecystectomy, predictive factors, preoperative scoring.
\end{abstract}

\section{Introduction}

Cholelithiasis is a common ailment and affects about 10 to $15 \%$ of general population. ${ }^{1}$ Laparoscopic cholecystectomy is one of the most common surgeries performed and has replaced open cholecystectomy. Since the introduction of laparoscopic cholecystectomy, the number of cholecystectomy perform in the United States has increased from 5 Lakh per year to 7 Lakh per year. $^{2}$

Cholelithiasis is the most common biliary pathology. Gallstones are present in 10 to $15 \%$ 
of the general population and asymptomatic in the majority $(>80 \%)$. The prevalence of gallstone varies widely in different parts of the world. In India it is estimated to be around 4\%. An epidemiological study restricted to rail road workers showed that north Indians have 7 times higher occurrence of gallstones as compared to south Indians. ${ }^{3}$ It is estimated that at least 20 million people in the United States have gallstones and that approximately 1 million new cases of cholelithiasis develop each year. Changing incidence in India is mainly attributed to westernization and availability of investigation that is ultrasound in both rural and urban areas and due to change in socioeconomic structure. $^{4}$

Approximately $1-2 \%$ of asymptomatic patients will develop symptoms requiring cholecystectomy per year, making cholecystectomy one of the most common operation performed by general surgeons. Cholelithiasis is rare in the first two decades. Incidence gradually increases after 21 years and reaches its peak in $5^{\text {th }}$ and $6^{\text {th }}$ decade. Women are more affected than men in the ratio of $4: 1 .^{4}$

In 1992, The National Institute of Health (NIH) consensus development conference stated that laparoscopic cholecystectomy "provides a safe and effective treatment for most patients with symptomatic gallstones." ${ }^{3}$ Since the introduction of laparoscopic cholecystectomy, the number of cholecystectomy performed in the United States has increased from 5 lakh per year to 7 lakh per year. ${ }^{5}$

The advantages of laparoscopic cholecystectomy over open cholecystectomy are earlier return to bowel functions, less postoperative pain, informed cosmesis, shorter length of hospital stay, earlier return to full activity, and decreased overall cost. 6-8 Laparoscopic cholecystectomy is associated with better preservation of immune function and a reduction of the inflammatory response compared with open surgery. The rate of postoperative infections seems to be lower. ${ }^{9}$
Since the conversion rate from laparoscopic cholecystectomy to open cholecystectomy is 1.5 to $19 \%$, there is a need to evaluate various factors responsible for difficult laparoscopic cholecystectomy.

Hence in the present study was done to evaluate the predictive factors responsible for difficult laparoscopic cholecystectomy.

\section{Materials and Methods \\ Study Design}

The present study was prospective analytical study carried out on patients diagnosed as cholelithiasis/ cholecystitis who are clinically evaluated and confirmed by ultrasonography in a tertiary care centre.

\section{Study Period}

The present study period was from December 2016 to June 2018.

\section{Study Population}

The study population was patients diagnosed as cholelithiasis/cholecystitis who are clinically evaluated and confirmed by ultrasonography in Krishna Institute of Medical Sciences.

\section{Sample Size}

A total sample size of 67 patients during study period diagnosed as cholelithiasis/ cholecystitis who are clinically evaluated and confirmed by ultrasonography was included in the study population.

\section{Inclusive Criteria}

- Patients aged between 18 to 60 years

- Symptoms and signs of Cholelithiasis / cholecystitis and diagnosed by USG examination.

\section{Exclusion Criteria}

- Patients below 18 years of age.

- Patients with CBD calcu1us, raised ALP, dilated

- CBD, where CBD exploration was needed.

- Patients with features of obstructive jaundice.

- Patients refusing surgery.

- Patients not willing for laparoscopic cholecystectomy. 


\section{Ethical Consideration}

The study was approved by the Ethical Committee of the Medical College.

\section{Data Collection}

- All patients diagnosed as cholelithiasis/ cholecystitis were selected

- Informed consent was taken from the patients.

- The selected subjects were visited and the questionnaire was administered.

- The patients confirmed by USG examination was evaluated with following risk factors like age, sex, previous attack of cholecystitis , Abdominal scarsupraumbilical or infraumbilical, BMI, gallbladder wall thickening $(>4 \mathrm{~mm})$, pericholecystic collection, impacted stone.

- Following evaluation the patient was subjected to laparoscopic cholecystectomy and time taken during surgery, biliary / stone spillage, injury to duct / artery and any probable need for open conversion was noted.

- All of the cases were operated by single laparoscopic surgeon.

- Post operatively cases were followed up for any complication.

- All patients were followed up for recurrent symptoms.

\section{Statistical Analysis}

- Data entered into Microsoft excel data sheet and analysed using SPSS 22 version software

- Categorical data represented in frequencies and proportions

- Fischer exact test was used as test of significance.

$P$ value $<0.05$ considered statistically significant.

\section{Observations and Results}

Table 1: Age distribution among patients

\begin{tabular}{|l|c|c|}
\hline Age group (years) & No of Patients & Percentage \\
\hline$<20$ & 04 & 05.97 \\
\hline $21-30$ & 13 & 19.40 \\
\hline $31-40$ & 18 & 26.87 \\
\hline $41-50$ & 13 & 19.40 \\
\hline $51-60$ & 19 & 28.36 \\
\hline Total & 67 & 100 \\
\hline
\end{tabular}

The above table shows age distribution among patients. The maximum numbers of cases were in the age group of 51-60 years $(28.36 \%)$, followed by in $41-40$ years $(26.87 \%)$.

Table 2: Sex distribution among patients

\begin{tabular}{|l|c|c|}
\hline Sex & No of Patients & Percentage \\
\hline Male & 21 & 31.34 \\
\hline Female & 46 & 68.66 \\
\hline Total & 67 & 100 \\
\hline
\end{tabular}

The above table shows sex distribution among patients. Out of 67 cases females $(68.66 \%)$ were the most affected when compared to males $(31.34 \%)$.

Table 3: Presenting complaints among patients

\begin{tabular}{|l|c|c|}
\hline Complaints & $\begin{array}{c}\text { No of Patients } \\
(\mathrm{n}=67)\end{array}$ & Percentage \\
\hline Pain & 67 & 100 \\
\hline Vomiting & 33 & 49.25 \\
\hline Jaundice & 04 & 05.97 \\
\hline Dyspepsia & 13 & 19.41 \\
\hline Fever & 06 & 08.96 \\
\hline
\end{tabular}

The above table shows presenting complaints among patients. The mode of presentation in the present study was pain (100\%), followed by vomiting (49.25\%), dyspepsia (19.41\%) and fever $(8.96 \%)$.

Table 4: Presenting signs among patients

\begin{tabular}{|l|c|c|}
\hline Signs & $\begin{array}{c}\text { No of Patients } \\
(\mathrm{n}=67)\end{array}$ & Percentage \\
\hline $\begin{array}{l}\text { Tenderness In Right } \\
\text { Hypochondrium }\end{array}$ & 46 & 68.66 \\
\hline Guarding & 04 & 05.97 \\
\hline Mass & 04 & 05.97 \\
\hline
\end{tabular}

The above table shows presenting signs among patients. The major sign in the present study was tenderness in right hypochondrium (68.66\%), followed by guarding (5.97\%) and abdominal mass $(5.97 \%)$. 
Table 5: BMI among patients

\begin{tabular}{|l|c|c|}
\hline BMI $\left(\mathrm{kg} / \mathrm{m}^{2}\right)$ & No of Patients & Percentage \\
\hline $\begin{array}{l}\text { Normal } \\
(18.5-24.9)\end{array}$ & 37 & 55.22 \\
\hline $\begin{array}{l}\text { Overweight } \\
(25.0-29.9)\end{array}$ & 16 & 23.88 \\
\hline Obese $(>30)$ & 14 & 20.90 \\
\hline Total & 67 & 100 \\
\hline
\end{tabular}

The above table shows BMI among patients. It was observed that majority of patients with normal BMI $(55.22 \%)$ followed by overweight $(23.88 \%)$ and obese $(20.09 \%)$

Table 6: USG findings among patients

\begin{tabular}{|l|c|c|}
\hline USG findings & $\begin{array}{c}\text { No of Patients } \\
(\mathrm{n}=67)\end{array}$ & Percentage \\
\hline Multiple calculi & 43 & 64.18 \\
\hline Solitary calculi & 13 & 19.40 \\
\hline $\begin{array}{l}\text { Solitary impacted } \\
\text { calculi }\end{array}$ & 09 & 13.43 \\
\hline Wall thickening & 18 & 26.87 \\
\hline $\begin{array}{l}\text { Pericholecystic } \\
\text { collection }\end{array}$ & 07 & 10.45 \\
\hline
\end{tabular}

The above table shows USG findings among patients. It was observed that majority of patients with multiple calculi $(64.18 \%)$ followed by gall bladder wall thickening (26.87\%), solitary calculi (19.40\%), impacted calculi $(13.43 \%)$ and pericholecystic collection $(10.45 \%)$

Table 7: Pre operative score among patients

\begin{tabular}{|l|c|c|}
\hline $\begin{array}{l}\text { Pre operative } \\
\text { score }\end{array}$ & No of Patients & Percentage \\
\hline $0-5$ & 49 & 73.13 \\
\hline $6-10$ & 17 & 25.38 \\
\hline $11-15$ & 01 & 01.49 \\
\hline Total & 67 & 100 \\
\hline
\end{tabular}

The above table shows pre operative score among patients. It was observed that majority of patients with score of $0-5(73.13 \%)$ followed by $6-10$ $(25.38 \%)$ and $11-15(1.49 \%)$

Table 8: Outcome among patients

\begin{tabular}{|l|c|c|}
\hline Outcome & No of Patients & Percentage \\
\hline Easy & 48 & 71.64 \\
\hline Difficult & 13 & 19.40 \\
\hline Very difficult & 06 & 08.96 \\
\hline Total & 67 & 100 \\
\hline
\end{tabular}

The above table shows outcome among patients. It was observed that majority of patients with easy outcome $(71.64 \%)$ followed by difficult $(19.40 \%)$ and very difficult $(8.96 \%)$ Out of 67 patients, 6 patients were operated for open cholecystectomy. So, the rate of conversion from laproscopic cholecystectomy to open cholecystectomy was $8.96 \%$.

Table 9: Frequency of intraoperative events leading to difficult procedure

\begin{tabular}{|l|c|c|}
\hline Intra-operative events & $\begin{array}{c}\text { No of patients } \\
(\mathrm{n}=19)\end{array}$ & Percentage \\
\hline $\begin{array}{l}\text { Dense adhesions at } \\
\text { Calot's triangle }\end{array}$ & 13 & 68.42 \\
\hline Visceral injury & 01 & 05.26 \\
\hline Stone/biliary spillage & 07 & 36.84 \\
\hline $\begin{array}{l}\text { Vascular } \\
\text { injury/significant } \\
\text { bleeding }\end{array}$ & 08 & 42.10 \\
\hline
\end{tabular}

The above table shows intraoperative events leading to difficult procedure among patients. Out of 19 patients with difficult and very difficult procedure majority of patients had Dense adhesions at Calot's triangle $(68.42 \%)$ followed by significant bleeding (42.10\%), biliary spillage $(36.84 \%)$ and visceral injury $(5.26 \%)$

Table 10: Correlation of Pre operative score and Outcome among patients

\begin{tabular}{|l|c|c|c|c|}
\hline $\begin{array}{l}\text { Pre operative } \\
\text { score }\end{array}$ & Easy & Difficult & $\begin{array}{c}\text { Very } \\
\text { difficult }\end{array}$ & Total \\
\hline $0-5$ & 47 & 02 & 00 & 49 \\
\hline $6-10$ & 01 & 11 & 05 & 17 \\
\hline $11-15$ & 00 & 00 & 01 & 01 \\
\hline Total & 48 & 13 & 06 & 67 \\
\hline
\end{tabular}

(X2=)

The above table shows Correlation of Pre operative score and Outcome among patients. There was a statistical significant positive correlation between pre operative score and outcome. $(\mathrm{P}<0.05)$ The positive predictive value for easy prediction was $94.7 \%$ and for difficult prediction was $100 \%$. 


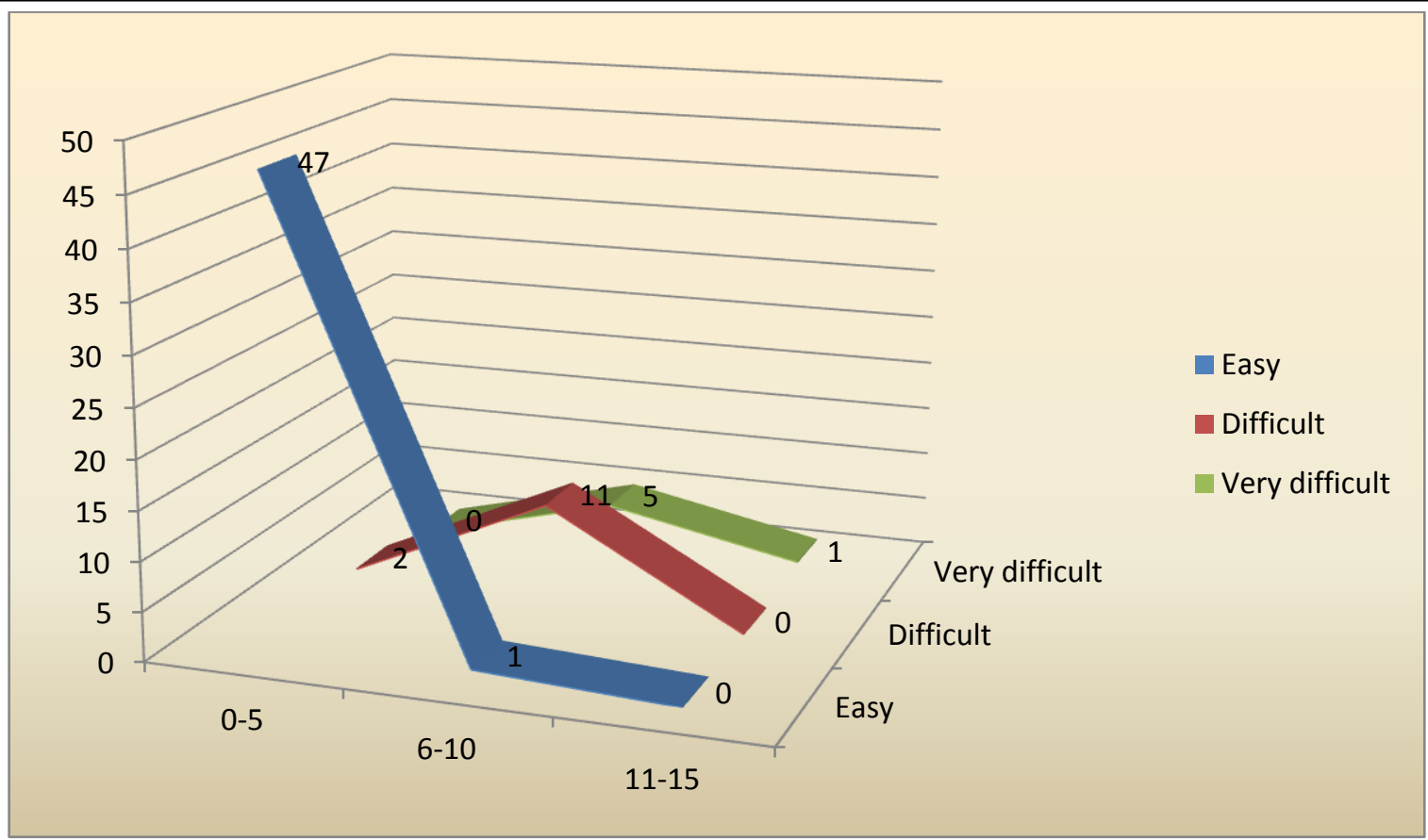

Figure 1: Correlation of Pre operative score and Outcome among patients

Table 11: Showing the analysis of Pre-operative Score with the risk factors

\begin{tabular}{|c|c|c|c|c|}
\hline \multirow[t]{2}{*}{ Risk Factors } & \multirow[t]{2}{*}{ Level } & \multicolumn{2}{|c|}{ Pre-operative Score } & \multirow[t]{2}{*}{ P Value } \\
\hline & & Difficult & Easy & \\
\hline \multirow[t]{2}{*}{ Age } & $\leq 50 \mathrm{Y}$ & 9 & 33 & \multirow[t]{2}{*}{0.62} \\
\hline & $>50 \mathrm{Y}$ & 4 & 15 & \\
\hline \multirow[t]{2}{*}{ Sex } & Female & 10 & 31 & \multirow[t]{2}{*}{0.51} \\
\hline & Male & 03 & 17 & \\
\hline \multirow{3}{*}{ BMI $w t(k g) / h t\left(m^{2}\right)$} & $<25$ & 01 & 34 & \multirow[t]{3}{*}{$<0.0001 *$} \\
\hline & $25.0-29.9$ & 02 & 12 & \\
\hline & $\geq 30$ & 10 & 02 & \\
\hline \multirow{2}{*}{ Previous Surg. } & No & 09 & 36 & \multirow[t]{2}{*}{0.73} \\
\hline & Yes & 04 & 12 & \\
\hline \multirow[t]{2}{*}{$\mathrm{H} / \mathrm{O}$ acute cholecystitis } & No & 04 & 46 & \multirow[t]{2}{*}{$<0.0001^{*}$} \\
\hline & Yes & 09 & 02 & \\
\hline \multirow[t]{2}{*}{ USG- Wall Thickness } & No & 02 & 40 & \multirow[t]{2}{*}{$<0.0001 *$} \\
\hline & Yes & 11 & 08 & \\
\hline \multirow[t]{2}{*}{ Impacted Stone } & No & 07 & 46 & \multirow[t]{2}{*}{$<0.001 *$} \\
\hline & Yes & 06 & 02 & \\
\hline \multirow[t]{2}{*}{ Pericholecystic Collection } & Nil & 08 & 44 & \multirow[t]{2}{*}{$0.01 *$} \\
\hline & Yes & 05 & 04 & \\
\hline
\end{tabular}

The above table shows association of Pre operative score with risk factors among patients. It was observed that BMI, H/O acute cholecystitis, thick wall, impacted stone and Pericholecystic collection showed statistical significant association $(\mathrm{P}<0.05)$ while age, sex and previous surgery showed no statistical significant association. $(\mathrm{P}>0.05)$

\section{Discussion}

The present prospective study was undertaken to determine the predictive factors for difficult laparoscopic cholecystectomy in a tertiary care centre.

The study was conducted in Department of Surgery from September 2016 to June 2018. A total sample size of 67 patients admitted in the department of various surgical wards in tertiary health center with diagnosis of cholelithiasis/ cholecystitis who were clinically evaluated and 
confirmed by USG included in the study population. Patients below 18 years of age, with CBD calculus, raised ALP, dilated, CBD, where CBD exploration was needed, obstructive jaundice ant not willing for laparoscopic cholecystectomy were excluded.

The study was conducted after taking ethical clearance from the institute and informed consent from the patients. The data was collected from patients regarding demographic profile, clinical spectrum findings with outcome.

\section{Age Distribution}

In the present study, the maximum numbers of cases were in the age group of 51-60 years (28.36\%), followed by in 41-40 years $(26.87 \%)$.

The present study was in concordance with the study of Herman's et $\mathrm{al}^{28}$; and studies of Hanif et $\mathrm{al}^{29}$ were the majority of patients were in the age group of 41-50 years.

Atul Kumar Gupta et $\mathrm{al}^{30}$ studied various predictors of difficulty and their correlation with likely difficulty observed out of 50 adults undergoing laparoscopic cholecystectomy for symptomatic cholelithiasis majority of patients in the age group of 31-40 years (18 out of 50).

Nikhil Agrawal et $\mathrm{al}^{31}$ studied preoperative prediction of difficult laparoscopic cholecystectomy by scoring method observed the mean age group of the study was $39.47 \pm 12.08$ years with the minimum age being 18 years and the maximum being 64 years. The majority of patients were in the age group of $\leq 50$ years ( 25 patients) and only $16.7 \%$ (five cases) were $>50$ years.

Shiv K. Bunkar et al evaluate pre-operative factors predicting difficult laparoscopic cholecystectomy observed majority were in the group 20-40 years of age (80 patients, $80 \%$ ).

\section{Sex Distribution}

In the present study, out of 67 cases females $(68.66 \%)$ were the most affected when compared to males $(31.34 \%)$. Higher incidence of gallstone in females has been suggested due to the effect of estrogen and progesterone on biliary cholesterol level and gallbladder motility.
The findings were in concordance with the study of Battachary ${ }^{33}$ and Hanif et al. ${ }^{29}$ Both studies showed $71.4 \%$ \& $64 \%$ of the patients were females and $28.6 \%$ \& $36 \%$ were males respectively.

Atul Kumar Gupta et $\mathrm{al}^{30}$ studied various predictors of difficulty and their correlation with likely difficulty observed out of 50 adults there were 45 females and 5 males.

Nikhil Agrawal et $\mathrm{al}^{31}$ studied preoperative prediction of difficult laparoscopic cholecystectomy by scoring method observed out of the 30 patients included in the study, 6 patients were male (20\%) and 24 were females (80\%).

Shiv K. Bunkar et $\mathrm{al}^{32}$ evaluate pre-operative factors predicting difficult laparoscopic cholecystectomy observed out of 100 cases 11 (11\%) were males and 89 (89\%) were females.

\section{Presenting Complaints}

\section{Pain}

Chronic recurring pain was the main symptom seen in all 67 patients. In $76.12 \%$ (51) of patients, pain was in the right hypochondrium. Of the 67 patients, $52.23 \%$ (35) patients had colicky type of pain. Radiation of pain to back was seen in 14 (20.89\%).

Pain was the most common symptom in both Ganey's series $^{34}$ and Alok sharma series. ${ }^{35}$

\section{Vomiting}

Vomiting was present in $33(49.25 \%)$ of the patients. Vomiting was spontaneous and associated with the attack of pain. This was consistent with Ganey et $\mathrm{al}^{34}$ and Alok Sharma et $\mathrm{al}^{35}$ study.

\section{Jaundice}

Four $(5.97 \%)$ patients had clinical jaundice, which was found to be obstructive type on further investigation. Later, patients underwent ERCP with CBD stenting, which was followed by Laparoscopic cholecystectomy after 6 weeks.

\section{Dyspepsia}

Dyspepsia was seen in $19.41 \%$ (13) of the patients. This is concordance with Ganey's series $^{34}$ and Alok Sharma series. ${ }^{35}$ 


\section{Fever}

Fever was observed in $8.96 \%$ (6) of the patients which was of moderate degree. This symptom is consistent with Ganey's series ${ }^{34}$ and Alok Sharma series. $^{35}$

\section{Physical Examination Findings}

In the present study, it revealed that majority of patients with normal BMI (55.22\%) followed by overweight $(23.88 \%)$ and obese $(20.09 \%)$

This was in concordance with the study of of $\mathrm{J} \mathrm{S}$ Randhawa et $\mathrm{al}^{36}$ and A K Pujahari et al. ${ }^{37}$

Nikhil Agrawal et $\mathrm{al}^{31}$ studied preoperative prediction of difficult laparoscopic cholecystectomy by scoring method observed 6 patients with body mass index $(\mathrm{BMI})>27.5 \mathrm{~kg} / \mathrm{m}$. Shiv K. Bunkar et $\mathrm{al}^{32}$ evaluate pre-operative factors predicting difficult laparoscopic cholecystectomy observed BMI of patients were $<25$ in $26(26 \%)$ patients; $25.1-30$ in $60(60 \%)$ patients and $>30$ in $14(14 \%)$ patients.

Obese patients may have a difficult laparoscopic surgery due to various factors. Port placement in obese patient takes longer time due to the thick abdominal wall. Dissection at the Calot's triangle is also technically difficult due to the obscure anatomy because of excessive intraperitoneal fat and difficulty in the manipulation of instruments through an excessively thick abdominal wall.

\section{Presenting Signs}

Tenderness in right hypochondrium was seen in $46(68.66 \%)$ patients. Tenderness was observed in more patients in the study of Hadfield et al. ${ }^{38}$

Guarding was found in $4(5.97 \%)$ patients in contrast to $18.7 \%$ seen in the study of Hadfield et al. ${ }^{38}$ Murphy's sign was positive in 19 (31\%) patients.

Mass was palpable in $4(5.97 \%)$ patients while in Hadfield's series ${ }^{38}$ mass was palpable in $7 \%$ of the patients

\section{Radiological Findings}

In all the patients, ultrasonography was performed as a routine investigation all 67 patients had stones in gallbladder. Gall bladder wall thickening was present in $18(26.87 \%)$ patients. Pericholecystic collection was seen in $7(10.45 \%)$ patients. Out of total 67 patients, 43 (64.18\%) cases had Multiple calculi, 13 (19.40\%) had Solitary calculi and 9 $(13.43 \%)$ had solitary impacted calculi.

In Alok Sharma et $\mathrm{al}^{35}$ study, $98.3 \%$ had stones in Gall Bladder and $5.2 \%$ had Gall Bladder wall thickening. Of the $98.3 \%, 73.7 \%$ had multiple stones, $26.3 \%$ had solitary stones and 5.2\% had bile duct stones. Similar findings were observed in the study of Bunker SK et al. ${ }^{32}$ the patients, ultrasonography was performed as a routine investigation.

\section{Correlation of Pre-Operative Score and the Outcome}

It was observed that majority of patients with score of $0-5(73.13 \%)$ followed by $6-10(25.38 \%)$ and 11-15 (1.49\%) It was observed that majority of patients with easy outcome $(71.64 \%)$ followed by difficult $(19.40 \%)$ and very difficult $(8.96 \%)$ Out of 67 patients, 6 patients were operated for open cholecystectomy. So, the rate of conversion from laproscopic cholecystectomy to open cholecystectomy was $8.96 \%$.

Nikhil Agrawal et $\mathrm{al}^{31}$ studied preoperative prediction of difficult laparoscopic cholecystectomy by scoring method observed 17 patients scored easy (56.7\%) and 13 (43.3\%) were difficult and nil in very difficult group.

Shiv K. Bunkar et $\mathrm{al}^{32}$ evaluate pre-operative factors predicting difficult laparoscopic cholecystectomy observed score between 0-5 had easy laparoscopic cholecystectomy in $88.4 \%$ patients, difficult laparoscopic cholecystectomy in $6.4 \%$ patients and very difficult in $5.2 \%$ patients. Patients who score between 6-10 have difficult laparoscopic cholecystectomy in $78.9 \%$ patients and very difficult in $21.1 \%$ patients. Patient who score between 11-15 have very difficult laparoscopic cholecystectomy in $100 \%$ patients. In the present study the positive predictive value for easy prediction was $94.7 \%$ and for difficult prediction was $100 \%$.

Shiv K. Bunkar et $\mathrm{al}^{32}$ evaluate pre-operative factors predicting difficult laparoscopic cholecystectomy observed scoring system had a 
positive prediction value for easy prediction of $94 \%$ and for difficult prediction of $100 \%$.

Nikhil Agrawal et $\mathrm{al}^{31}$ studied preoperative prediction of difficult laparoscopic cholecystectomy by scoring method observed prediction came true in $76.4 \%$ for easy and $100 \%$ difficult cases.

In the studies of $\mathrm{J} S$ Randhawa et $\mathrm{al}^{36}$ and $\mathrm{A} \mathrm{K}$ Pujahari et al ${ }^{37}$ of the 228 cases studied; cases with 0 to 5 pre-op score were 178 of which 158 were easy Laparoscopic Cholecystectomy, 14 were difficult Laparoscopic Cholecystectomy and 6 were very difficult LC. The positive prediction value for easy prediction was $88.8 \%$ and for difficult prediction was $92 \%$. The conversion rate was $3 / 228$ i.e. $1.315 \%$ and all were due to anomaly in the ducts. The positive predictive value for easy prediction was $94.7 \%$ and for difficult prediction was $100 \%$.

The conversion rate from laparoscopic cholecystectomy to open cholecystectomy was $8.96 \%$ which was in concordance with the of study of Kama et al. ${ }^{39}$

Atul Kumar Gupta et $\mathrm{al}^{30}$ studied various predictors of difficulty and their correlation with likely difficulty observed conversion to open cholecystectomy was needed only in two patients $(4 \%)$.

Nikhil Agrawal et $\mathrm{al}^{31}$ studied preoperative prediction of difficult laparoscopic cholecystectomy by scoring method observed the proposed scoring system was reliable with a sensitivity of $76.47 \%$ and specificity of $100 \%$.

\section{Analysis of Pre-Operative Score with the Risk Factors}

In the present study, it was observed that BMI, $\mathrm{H} / \mathrm{O}$ acute cholecystitis, thick wall, impacted stone and Pericholecystic collection showed statistical significant association $(\mathrm{P}<0.05)$ while age, sex and previous surgery showed no statistical significant association. $(\mathrm{P}>0.05)$

Nikhil Agrawal et $\mathrm{al}^{31}$ studied preoperative prediction of difficult laparoscopic cholecystectomy by scoring method observed factors like previous history of hospitalization, clinically palpable gallbladder, impacted GB stone, pericholecystic collection, and abdominal scar due to previous abdominal surgery were found statistically significant in predicting difficult LC.

Shiv K. Bunkar et $\mathrm{al}^{32}$ evaluate pre-operative factors predicting difficult laparoscopic cholecystectomy observed $\mathrm{BMI}>30$, previous medical disease like DM, palpable gall bladder, prior hospitalization pericholecystic collection and impacted stone are significant risk factors to predict difficult laparoscopic cholecystectomy.

Atul Kumar Gupta et $\mathrm{al}^{30}$ studied various predictors of difficulty and their correlation with likely difficulty observed clinical predictors like duration of symptoms $>1 \mathrm{yr}$, history of acute cholecystitis and BMI >30 showed statistically significant association. Age $>50 \mathrm{yrs}$, Male gender, radiological predictors (Thickened gall bladder wall, small contracted gall bladder, Single large impacted stone) and deranged LFT did not show significant predictive value.

It is presumed that previous abdominal surgery; especially upper abdominal surgery may cause difficulty due to periumbilical and peri gallbladder adhesions. Nachnani et $\mathrm{al}^{40}$ reported that previous abdominal surgery poses problems during creation of pneumoperitoneum and during adhesiolysis to gain adequate exposure to the operative field. But Kanaan et $\mathrm{al}^{41}$ and Lipman et $\mathrm{al}^{42}$ did not find prior abdominal surgery as a significant risk factor for conversion or prediction of difficult laparoscopic cholecystectomy.

In the present study, complications among patients showed out of 67 patients only 2 (2.98\%) patients had wound infection.

Shiv K. Bunkar et $\mathrm{al}^{32}$ evaluate pre-operative factors predicting difficult laparoscopic cholecystectomy observed postoperative complication was seen in four patients who developed an infection of the epigastric port site.

The preoperative scoring is statistically and clinically a good test for predicting the operative outcome in LC. In the present study, sample size was small but the predictors of difficult LC 
correlated well with previous studies. Further randomized prospective trial with large sample size needed to validate the scoring system.

\section{Summary}

The present prospective study was undertaken to determine the predictive factors for difficult laparoscopic cholecystectomy in a tertiary care centre.

The study revealed following:

- The maximum numbers of cases were in the age group of 51-60 years $(28.36 \%)$, followed by in $41-40$ years $(26.87 \%)$.

- Out of 67 cases females (68.66\%) were the most affected when compared to males $(31.34 \%)$.

- Chronic recurring pain was the main symptom seen in all 67 patients.

- In $76.12 \%$ (51) of patients, pain was in the right hypochondrium. Of the 67 patients, $52.23 \%$ (35) patients had colicky type of pain. Radiation of pain to back was seen in14 (20.89\%).

- Vomiting was present in 33 (49.25\%) of the patients. Vomiting was spontaneous and associated with the attack of pain.

- Four (5.97\%) patients had clinical jaundice, which was found to be obstructive type on further investigation.

- Dyspepsia was seen in $19.41 \%$ (13) of the patients.

- Fever was observed in $8.96 \%$ (6) of the patients which was of moderate degree.

- The majority of patients with normal BMI $(55.22 \%)$ followed by overweight $(23.88 \%)$ and obese $(20.09 \%)$

- Tenderness in right hypochondrium was seen in $46(68.66 \%)$ patients.

- Guarding was found in $4(5.97 \%)$ patients. Murphy's sign was positive in 19 (31\%) patients.

- Mass was palpable in $4(5.97 \%)$ patients .

- Gall bladder wall thickening was present in $18(26.87 \%)$ patients.
- Pericholecystic collection was seen in 7 (10.45\%) patients.

- $\quad$ Out of total 67 patients, $43(64.18 \%)$ cases had Multiple calculi, $13(19.40 \%)$ had Solitary calculi and $9(13.43 \%)$ had solitary impacted calculi.

- It was observed that majority of patients with score of 0-5 (73.13\%) followed by 6$10(25.38 \%)$ and $11-15(1.49 \%)$

- It was observed that majority of patients with easy outcome $(71.64 \%)$ followed by difficult $(19.40 \%)$ and very difficult $(8.96 \%)$

- Out of 67 patients, 6 patients were operated for open cholecystectomy. So, the rate of conversion from laproscopic cholecystectomy to open cholecystectomy was $8.96 \%$.

- In the present study the positive predictive value for easy prediction was $94.7 \%$ and for difficult prediction was $100 \%$.

- The conversion rate from laparoscopic cholecystectomy to open cholecystectomy was $8.96 \%$.

- It was observed that BMI, H/O acute cholecystitis, thick wall, impacted stone and Pericholecystic collection showed statistical significant association $(\mathrm{P}<0.05)$ while age, sex and previous surgery showed no statistical significant association. $(\mathrm{P}>0.05)$

- Complications among patients showed out of 67 patients only $2(2.98 \%)$ patients had wound infection.

\section{Conclusion}

The preoperative scoring is statistically and clinically a good test for predicting the operative outcome in LC.

The study concluded that history of previous abdominal surgery, tenderness in the right hypochondrium, and thickening of GB, whereas conversion to OP was significantly high in patients with thickening of GB and distended or contracted GB. Among demographic parameters, 
BMI $>30 \mathrm{~kg} / \mathrm{m}$ was the significant predictor of difficult LC and conversion. This consequently increases the operating time of such patients. This can contribute to the quest for surgical excellence and better patient care for one of the most commonly performed surgical procedures in the world.

\section{References}

1. Kurin Conlon. Gallbladder and bile ducts $25^{\text {th }}$ edition. Chatper 63 in Bailey and Love's short practice of Surgery, Norman S. Williams, Christopher J.K. Bulstrode, P. Ronan O'Connell. 2017: 1119-1120.

2. Ravi S. Chari,MD and Shinul A. Shah,MD. Biliary system, Chapter 54 Sabiston textbook of surgery, Volume 2, $18^{\text {th }}$ edition, Courtney M. Town Send, R. Laniel Beauchamp, B. Mark Evers, Kenneth.L. Mattox, 2016: 1547-1588.

3. Rakesh Tendon, "Diseases of gallbladder and biliary tract". API text book of medicine, Dr. Siddarth N Shah, 7th edition, 2003, PP $642-644$.

4. S. Das Biliary System. Chapter 38 In: A Concise Textbook Of Surgery, Das S 6th Edition. Sumanth Das, July 2010.

5. Conference, $\mathrm{N}$ C. Gallstones and laparoscopic cholecystectomy: JAMA 1992; 269: 1018-1024.

6. Barkun J S, Barkun A N, Sampalis J S, et al. Randomized Controlled Trial Of Laparoscopic Versus Mini-Cholecystectomy. Lancet 1992:340:1116-1119.

7. Bass E B, Pitt H A, Lillenore K D. Cost Effectiveness Of Laparoscopic Cholecystectomy Versus Open Cholecystectomy. Am J Surg 1993;165:466-471.

8. Soper N, Barteau J, Clayman R, Et Al. Laparoscopic Versus Standard Open Cholecystectomy: Comparision Of Early Results. Surg Gynaecol Obstet 1992; 174:114-118.

9. Boni L, et al. Infective complication of laparoscopic surgery. Surg infect (Larchmt), 2006; 7 suppl 2: S109-11.

10. Jermiah S Healy, Neil R Borley, Caroline Wigley, editors. Gall bladder and biliary tree. Susan standring, editor. Gray's anatomy : the anatomical basis of clinical practice. 39th edition, Elsevier Churchill livingstone , 2005. chapter 86, PP:12271231.

11. L. H. Blumgart, L. E. Hann; Surgical and Radiological anatomy of the liver, biliary tract and pancreas. Leslie $\mathrm{H}$ Blumgart, Surgery of the Liver, Biliary tract, and Pancreas, 4th edition, Elsevier-Saunders, 2007. Chapter 1, PP:3-30.

12. Sir Alfred Cuscheri, "Disorder of the biliary tract". Textbook of surgery, Sir Alfred Cuscheri, 4th edition, Arnold publication, 2002 PP:375-453.

13. T.W. Sadler. Liver and gallbladder and pancreas; Digestive System. Langman's Medical Embryology, 7th edition, Elsevier. Chapter 14, 2016;PP:254-258.

14. Alexander P Nagle, Nathaniel J Soper, James R Hines; Colecystectomy (open and laparoscopic).Michael J Zinner, Stanley W Ashley; Maingot's Abdominal Operations; $11^{\text {th }}$ edition, Mc Graw Hill, 2007. Chapter 32, PP:847-864.

15. Ransohoff D, Gracie W, Wolfenson L, Et Al. Prophylactic cholecystectomy or expectant management of silent gallstones: a decision analysis to assess survival. Ann inter med 1983; 99: 199204.

16. Tagge E, Otherson H J, Jacksons, Et Al. Impact of laparoscopic cholecystectomy on the management of cholelithiasis in children with sickle cell disease. J Pediats Surg 1994; 29: 209-212.

17. Hull D, Bartus S, Perdrizet G, Et Al. Management of cholelithiasis in heart and lung transplant patients: with review of laparoscopic cholecystectomy. Conn Med 1994; 58: 643-647. 
18. Sopr N. Laparoscopic cholecystectomy. Curr Probl Surg 1999; 28: 585-655.

19. Laparoscopic cholecystectomy. C Palanivellu; Foreward: Jacques Perissat, Horacio J Asbun; Art of Lparoscopic Surgery, textbook and atlas; 1st edition,Jaypee,2005. Chapter 36, PP:555585.

20. Way L W, Stewart L, Gantert W, et al. Causes and prevention of laparoscopic bile duct injuries: analysis of 252 cases from a human factors and cognitive psychology perspective. Ann Surg 2003; 4:460.

21. Heng-Hui Lein MD, Ching-Shui Huang. Male gender: Risk factor for severe sympatomatic cholelithiasis. World J Surg 2002; 26:598-601.

22. Fried GM, Barkun JS, Sigman HH, Joseph L, Uas D, Garzon J, Hinchey EJ, Meakins $\mathrm{JL}$ Factors determining conversion to laparotomy in patients undergoing laparoscopic cholecystectomy. Am J Surg. 1994 Jan;167(1):35-9.

23. Ahmet Alponat, Cheng $\mathrm{K}$, Bee $\mathrm{C}$ Koh, Andrea R, Peter MY Goh Predictive factors for conversion of laparoscopic cholecystectomy. World J Surg 1997;21:629-633.

24. Pichler.J.M., "Primary carcinoma of gallbladder." Surgery, Gynecology and Obstetrics, 1978, 147: PP 929-942.

25. Schrenk P, Woisetschlager R, Reiger R, et al. Preoperative ultrasonsgraphy and prediction of difficulties in laparoscopic cholecystectomy. World J Surg 1998; 22:75-77.

26. Difficult cholecystectomy. C Palanivellu; Foreward: Jacques Perissat, Horacio J Asbun; Art of Lparoscopic Surgery, textbook and atlas; 1st edition,Jaypee, 2005. Chapter 39, PP:607-635.

27. Jorgensen J O, Hunt D R: laparoscopic cholecystectomy. A prospective analysis of the potential causes of failure. Surg laparos endosc 3: 49- 53, 1993.
28. Hermann R E.“ Biliary Disease In The Aging Patients.", New York, Masson, 1983, PP. 227-232.

29. Hanif G Motiwala: Operative Technique Cholecystectomy. A Study Of 250 Cases: Surgery In The Tropics . Ed: Sakens: Jhawes Pk: Purohit A : Mc Millan India Ltd. , 1991, 56, 204.

30. Gupta AK, Shiwach N, Gupta S, Gupta S, Goel A, Bhagat TS. Predicting difficult laparoscopic cholecystectomy. Int Surg J 2018;5:1094-9.

31. Nikhil Agrawal, Sumitoj Singh, and Sudhir Khichy. Preoperative Prediction of Difficult Laparoscopic Cholecystectomy: A Scoring Method Niger J Surg. 2015 JulDec; 21(2): 130-133.

32. Bunkar SK, Yadav S, Singh A, Agarwal K, Sharma P, Sharma AC. Factors predicting difficult laparoscopic cholecystectomy: a single institution experience. Int Surg J 2017;4:1743-7.

33. Bhattacharya R, “ Cholecystectomy In West Port, New Zealand.”, Indian Journal Of Surgery, Aug 1983, PP.450-455.

34. Ganey J B, “ Cholecystectomy: Clinical Experience With A Large Series", Am J Surg, 1986, PP. 352-357.

35. Maj. Alok Sharma, "Towards A Safer Cholecystectomy- The Fundus Porta Approach", Indian Journal Of Surgery, June 1997, PP. 141-145.

36. J. S. Randhawa . A. K. Pujahari, preoperative prediction of difficult lap chole: a scoring method. Indian Journal of Surgery, volume 71, number 4, JulyAugust 2009, PP:198-201.

37. Haziq Ul Yaqin, Hadfield: Chronic Cholecystitis, International Surgery, 1970.

38. Kama N A, Dogary M, Dolapa M. Reise, Attli $\mathrm{M}$, et al Risk factors resulting in conversion of laparoscopic cholecystectomy to open cholecystectomy. Surgical endoscopy, Springer New York; 2001; Vol 15 : 965-968. 
39. Nachnani J, Supe A. Pre-operative prediction of difficult laparoscopic c oscopic c oscopic cholecystectomy using clinical and ultrasonographic parameters. Indian J Gastroenterol. 2005 JanFeb;24(1):16-8.

40. Kanaan SA, Murayama KM, Merriam LT, Dawes LG, Puystowsky JB, Reye RB, Jochi RJ. Risk factors for conversion of laparoscopic to open cholecystectomy. J Surg Res 2002; 106:20-24.

41. Lipman JM, Claridge JA, Haridas M, Martin MD, Yao DC, Grimes KL, et al. Preoperative findings predict conversion from laparoscopic to open cholecystectomy. Surg. 2007;142:556-65. 